\title{
Sistem Pendukung Keputusan Dalam Pemilihan Pergururan Tinggi Terbaik Dengan Menggunakan Metode SAW (Simple Additive Weighting)
}

\author{
Arief Budiman, Yuyun Dwi Lestari, Yessi Fitri Annisah Lubis \\ Universitas Harapan, Medan, Indonesia ${ }^{1,2,3}$ \\ Email : arief.budiman.stth@gmail.com ${ }^{1}$, yuyun.dl@gmail.com², yessy.annisa@gmail.com ${ }^{3}$
}

\begin{abstract}
Abstrak
Banyaknya Perguruan Tinggi khususnya di kota Medan dengan menawarkan kelebihan masing-masing mulai dari akreditas, fasilitas dan lain sebagainya, membuat calon mahasiswa bingung untuk memilih Perguruan Tinggi terbaik di kota Medan. Untuk dapat memilih Perguruan Tinggi calon mahasiswa melakukan survey terlebih dahulu tentang informasi masing-masing Perguruan Tinggi yang khsususnya berada di kota Medan. Dengan menggunakan Sistem Pendukung Keputusan maka sebuah permasalahan dapat mudah teratasi dengan cepat khususnya mengenai pemilihan dalam menentukan Perguruan Tinggi terbaik di kota Medan. Dalam penelitian ini Sistem Pendukung Keputusan yang dibuat menggunakan metode Simple Additive Weighting. SAW lebih efisien karena waktu yang dibutuhkan dalam perhitungan lebih singkat.
\end{abstract}

Kata Kunci :Perguruan Tinggi, Sistem Pendukung Keputusan, Metode SAW

\section{Abstract}

The number of universities, especially in the city of Medan by offering their respective advantages ranging from accreditation, facilities, etc., makes prospective students confused to choose the best university in the city of Medan. To be able to choose a university prospective students do a survey in advance about the information of each university which is specifically located in the city of Medan. By using a Decision Support System, a problem can be easily resolved quickly, especially regarding the election in determining the best university in the city of Medan. In this study a Decision Support System was made using the Simple Additive Weighting method. SAW is more efficient because the time needed in calculations is shorter.

Keywords: Higher Education, Decision Support System, SAW Method 


\section{PENDAHULUAN}

Perguruan Tinggi merupakan suatu wadah dimana seseorang akan melanjutkan studi lanjutan dari sekolah menengah atas (SMA) agar dapat memfokuskan bidang kemampuannya untuk menuju masa depan yang diinginkan. Banyaknya Perguruan Tinggi khususnya di kota Medan dengan menawarkan kelebihan masing-masing mulai dari akreditas, fasilitas dan lain sebagainya, membuat calon mahasiswa bingung untuk memilih Perguruan Tinggi terbaik di kota Medan. Untuk dapat memilih Perguruan Tinggi calon mahasiswa melakukan survey terlebih dahulu tentang informasi masing-masing Perguruan Tinggi yang khsususnya berada di kota Medan. Dengan demikian nantinya calon mahasiswa tersebut dapat melakukan penilaian dari masing-masing Perguruan Tinggi tersebut, sehingga mereka dapat memastikan Perguruan Tinggi manakah yang terbaik untuk dijadikan sebagai lanjutan pendidikannya. Sistem Pendukung Keputusan merupakan suatu sistem berbasis komputer yang menghasilkan berbagai alternatif keputusan untuk membantu manajemen dalam menangani berbagai permasalahan yang terstruktur ataupun tidak terstruktur dengan menggunakan data dan model. Dengan menggunakan Sistem Pendukung Keputusan maka sebuah permasalahan dapat mudah teratasi dengan cepat khususnya mengenai pemilihan dalam menentukan Perguruan Tinggi terbaik di kota Medan. Dalam Sistem Pendukung Keputusan terdapat beberapa metode yang ada didalamnya. Metode tersebut digunakan untuk memudahkan peneliti dalam menganalisa sebuah masalah yang terdapat didalamnya agar dapat menentukan sebuah keputusan yang terbaik dari beberapa alternatif yang dimiliki. Untuk itu pada penelitian ini penulis akan menggunakan metode SAW (Simple Additive Weighting) di dalam menentukan Perguruan Tinggi terbaik agar calon mahasiswa dapat menentukan pilihannya sesuai yang mereka butuhkan.

\section{LANDASAN TEORI}

\section{a. Sistem Pendukung Keputusan}

Sistem Pendukung Keputusan adalah konsep spesifik sistem yang menghubungkan komputerisasi informasi dengan para pengambil keputusan sebagai pemakainya. Dengan demikian Sistem Pendukung Keputusan adalah seperangkat elemen yang digabungkan satu dengan yang lainnya saling bekerja sama untuk menghasilkan satu kesatuan di dalam pencapaian suatu tujuan bersama. (Riandari, dkk, 2017)

Definisi lain menurut Eniyati (2011), Sistem pendukung keputusan adalah suatu sistem berbasis komputer yang menghasilkan berbagai alternatif keputusan untuk membantu manajemen dalam menangani berbagai permasalahan yang terstruktur ataupun tidak terstruktur dengan menggunakan data dan model. Untuk menghasilkan keputusan yang baik di dalam sistem pendukung keputusan, perlu didukung oleh informasi dan fakta-fakta yang berkualitas antara lain

1. Aksebilitas

Atribut ini berkaitan dengan kemudahan mendapatkan informasi, informasi akan lebih berarti bagi si pemakai kalau informasi tersebut mudah didapat, karena akan berkaitan dengan aktifitas dari nilai informasinya.

2. Kelengkapan

Atribut ini berkaitan dengan kelengkapan isi informasi, dalam hal ini isi tidak menyangkut hanya volume tetapi juga kesesuaian dengan harapan si pemakai sehingga sering kali kelengkapan ini sulit diukur secara kuantitatif. 
3. Ketelitian

Atribut ini berkaitan dangan tingkat kesalahan yang mungkin di dalam pelaksanaan pengolahan data dalam jumlah (volume) besar.Dua tipe kesalahan yang sering terjadi yaitu berkaitan dengan perhitungan.

4. Ketepatan

Atribut ini berkaitan dengan kesesuaian antara informasi yang dihasilkan dengan kebutuhan pemakai.Sama halnya dengan kelengkapan, ketepatan pun sangat sulit diukur secara kuantitatif.

5. Ketepatan Waktu

Kualitas informasi juga sangat ditentukan oleh kektepatan wktu penyampaian dan aktualisasinya. Misal informasi yang berkaitan dengan perencanaan harian akan sangat berguna kalau disampaikan setiap dua hari sekali.

6. Kejelasan

Atribut ini berkaitan dengan bentuk atau format penyampaian informasi. Bagi seorang pimpinan, informasi yang disajikan dalam bentuk grafik, histogram, atau gambar biasanya akan lebih berarti dibandingkan dengan informasi dalam bentuk katakata yang panjang.

7. Fleksibilitas

Atribut ini berkaitan dengan tingkat adaptasi dari informasi yang dihasilkan terhadap kebutuhan berbagai keputusan yang akan diambil dan terhadap sekelompok pengambil keputusan yang berbeda.

b. Tujuan Sistem Pendukung Keputusan

Sistem Pendukung Keputusan tidak dimaksudkan untuk mengotomatisasikan pengambilan keputusan, tetapi memberikan perangkat interaktif yang memungkinkan pengambil keputusan untuk melakukan berbagai analisis menggunakan model-model yang tersedia. Tujuan dari sistem pendukung keputusan adalah (Zulita, 2013):

1. Membantu manajer dalam pengambilan keputusan atas masalah semiterstruktur

2. Memberikan dukungan atas pertimbangan manajer dan bukannya dimaksudkan untuk menggantikan fungsi manajer

3. Meningkatkan efektifitas keputusan yang diambil manajer lebih daripada perbaikan efesiensinya

4. Komputer memungkinkan para pengambil keputusan untuk melakukan banyak komputasi secara cepat dengan biaya yang rendah

5. Peningkatan produktifitas

6. Komputer bisa meningkatkan kualitas keputusan yang dibuat

7. Berdaya saing

8. Mengatasi keterbatasan kogntif dalam pemroresan dan penyimpanan

\section{c. Metode Simple Additive Weighting (SAW)}

Metode Simple Additive Weighting (SAW) sering juga dikenal istilah metode penjumlahan terbobot. Konsep dasar metode SAW adalah mencari penjumlahan terbobot dari rating kinerja pada setiap alternatif pada semua atribut. Metode SAW membutuhkan proses normalisasi matriks keputusan (X) ke suatu skala yang dapat diperbandingkan dengan semua rating alternatif yang ada. Metode ini merupakan metode yang paling terkenal dan paling banyak digunakan dalam menghadapi situasi Multiple Attribute Decision Making (MADM). MADM itu sendiri merupakan suatu metode yang digunakan untuk mencari alternatifoptimal dari sejumlah alternatif dengan kriteria tertentu.

Metode SAW ini mengharuskan pembuat keputusan menentukan bobot bagi setiap atribut. Skor total untuk alternatif diperoleh dengan menjumlahkan seluruh hasil perkalian 
antara rating (yang dapat dibandingkan lintas atribut) dan bobot tiap atribut. Rating tiap atribut haruslah bebas dimensi dalam arti telah melewati proses normalisasi matriks sebelumnya. Adapun langkah penyelesaian metode SAW adalah sebagai berikut : (Indrawaty,dkk.2011)

1. Menentukan kriteria-kriteria yang akan dijadikan acuan dalam pengambilan keputusan yaitu $\mathrm{Ci}$

2. Menentukan rating kecocokan setiap alternatif pada setiap criteria.

3. Membuat matriks keputusan berdasarkan kriteria(Ci), kemudian melakukan normalisasi matriks berdasarkan persamaan yang disesuaikan dengan jenis atribut (atribut keuntungan ataupun atribut biaya) sehingga diperoleh matriks ternormalisasi R.

4. Hasil akhir diperoleh dari proses perankingan yaitu penjumlahan dari perkalian matriks ternormalisasi $\mathrm{R}$ dengan vektor bobot sehingga diperoleh nilai terbesar yang dipilih sebagai alternatif terbaik (Ai)sebagai solusi.

Formula untuk melakukan normalisasi tersebut adalah :

$r_{i j}=\left\{\begin{array}{c}\frac{X i j}{M a x X i j} \quad \text { jika } j \text { adalah atribut keuntungan } \\ \frac{\text { MinXij }}{X i j} \quad \text { jika } j \text { adalah atribut biaya }\end{array}\right.$

Dimana :

rij $\quad=$ rating kinerja ternormalisasi

Maxij = nilai maksimum dari setiap baris dan kolom

Minij = nilai minimum dari setiap baris dan kolom

Xij = baris dan kolom dari matriks

Dengan rij adalah rating kinerja ternormalisasi dari alternatif Ai pada atribut $\mathrm{Cj} ; \mathrm{i}=1,2, \ldots \mathrm{m}$ dan $\mathrm{j}=1,2, \ldots, \mathrm{n}$.

Nilai preferensi untuk setiap alternatif (Vi) diberikan sebagai :

$V i=\sum_{j=1}^{n} w_{j} \cdot r_{i j}$

Dimana :

$\mathrm{Vi}=$ Nilai akhir dari alternative

$\mathrm{wj}=$ Bobot yang telah ditentukan

rij = Normalisasi matriks

Nilai Vi yang lebih besar mengindikasikan bahwa alternatif Ai lebih terpilih

d. Keuntungan Simple Additive Weighting (SAW)

Menurut Djmain (2015), Beberapa keuntungan dari metode Simple Additive Weighting (SAW) antara lain:

1. Simple Additive Weighting (SAW) memberikan suatu model yang mudah dimengerti, luwes untuk bermacam-macam persoalan yang tidak terstruktur.

2. Simple Additive Weighting (SAW) mencerminkan cara berpikir alami untuk memilahmilih elemenelemen dari suatu system ke dalam berbagai tingkat berlainan dan mengelompokan unsur yang serupa dalam setiap tingkat.

3. Simple Additive Weighting (SAW) memberikan suatu skala pengukuran dan memberikan metode untuk menetapkan prioritas. 
4. Simple Additive Weighting (SAW) memberikan penilaian terhadap konsistensi logis dari pertimbangan-pertimbangan yang digunakan dalam menentukan prioritas.

5. Simple Additive Weighting (SAW) menuntun ke suatu pandangan menyeluruh terhadap alternative yang muncul untuk masalah yang dihadapi.

6. Simple Additive Weighting (SAW) memberikan suatu sarana untuk penilaian yang tidak dipaksakan tetapi merupakan penilaian yang sesuai pandangan masing-masing.

7. Simple Additive Weighting (SAW) memungkinkan setiap orang atau kelompok untuk mempertajam kemampuan logic dan intuisinya terhadap persoalan yang dipetakan melalui Simple Additive Weighting (SAW).

e. Perguruan Tinggi

Istilah Perguruan Tinggi yang digunakan untuk lapisan ke-2, identic dengan istilah Perguruan Tinggi yang disebut dalam Peraturan Pemerintah No.30 th 1990, yaitu organisasi satuan pendidikan, yang menyelenggarakan pendidikan di jenjang pendidikan tinggi, penelitian dan pengabdian kepada masyarakat. Fungsi-fungsi utama Perguruan Tinggi adalah

1. Membina kualitas hasil dan kinerja Perguruan Tinggi, agar dapat memberi sumbangan yang nyata kepada perkembangan IPOLEKSOSBUD di masyarakat.

2. Merencanakan pengembangan Perguruan Tinggi menghadapi perkembangan di masyarakat.

3. Mengupayakan tersedianya sumberdaya untuk menyelenggarakan tugas-tugas fungsional dan rencana perkembangan Perguruan Tinggi. Sumberdaya diupayakan, tidak hanya Otoritas Pusat, tetapi juga dari pihak-pihak lain melalui kerjasama, kontrak penelitian, penyediaan pendidikan dan pelatihan khusus, sumbangan dan lainlain. (http://www.dikti.org/kpptjp/BAB_3.htm).

\section{METODE PENELITIAN}

Adapun metode penelitian yang penulis gunakan adalah :

1. Identifikasi Masalah

Pada tahapan ini penulis melakukan identifikasi terhadap masalah yang akan dibahas dan metode yang akan digunakan untuk menyelesaikan permasalahan.

2. Analisa Permasalahan

Pada tahap ini penulis melakukan analisa masalah terhadap masalah yang akan dibahas, sehingga masalah dapat dipahami dengan baik

3. Studi Literatur

Melakukan studi literatur untuk melihat apakah teori yang sudah dimiliki dapat dikembangkan serta mendapatkan landasan teori yang sesuai mengenai masalah dan metode yang diteliti.

4. Mengumpulkan Data Yang Dibutuhkan

Melakukan pengumulan data yang diperlukan untuk menunjang penelitian.

5. Menganalisis Data dan Metode

Pada tahap ini dilakukan analisis terhadap data-data dan menerapkannya pada metode yang digunakan sesuai dengan kriteria-kriterianya.

6. Implementasi Metode

Pada tahap ini dilakukan implementasi metode terhadap sampel data yang digunakan

7. Menetapkan Kesimpulan

Pada tahap ini dilakukan kesimpulan dari penerapan metode terhadap sampel data yang digunakan agar mendapatkan sebuah pengambilan keputusan. 


\section{Hasil dan Pembahasan}

\section{a. Kriteria Sistem Pendukung Keputusan Metode SAW}

Ada 5 Perguruan Tinggi yang akan menjadi Alternatif yaitu PT A1 = A, A2 = B, A3 $=\mathrm{C}, \mathrm{A} 4=\mathrm{D}$ dan $\mathrm{A} 5=\mathrm{E}$. Dan 5 kriteria yang akan dijadikan acuan dalam pengambilan keputusan yaitu:

$$
\begin{aligned}
& \mathrm{C} 1=\text { Akreditas } \\
& \mathrm{C} 2=\text { Fasilitas } \\
& \mathrm{C} 3=\text { Biaya } \\
& \mathrm{C} 4=\text { Lokasi } \\
& \text { C5 }=\text { Dosen }(\text { Pendidikan S2, S3) }
\end{aligned}
$$

Tabel 4.1 Kriteria Akreditas

Tabel 4.2 Kriteria Fasiltas

\begin{tabular}{|l|r|}
\hline Nilai Akreditas & Bobot \\
\hline A & 1 \\
\hline B & 0.75 \\
\hline C & 0.5 \\
\hline Tidak Ada & 0 \\
\hline
\end{tabular}

\begin{tabular}{|l|r|}
\hline Ket & Bobot \\
\hline Memadai & 1 \\
\hline Sedang & 0.75 \\
\hline Tidak & \\
Memadai & 0.5 \\
\hline
\end{tabular}

Tabel 4.3 Kriteria Biaya

\begin{tabular}{|l|r|}
\hline Ket & \multicolumn{2}{|l|}{ Bobot } \\
\hline Murah & 0.75 \\
\hline Sedang & 0.5 \\
\hline Mahal &
\end{tabular}

Tabel 4.4 Kriteria Lokasi

Tabel 4.5 Kriteria Dosen

\begin{tabular}{|l|l|r|}
\hline $\begin{array}{l}\text { Pendidikan } \\
\text { Dosen }\end{array}$ & Ket & Bobot \\
\hline$>75 \%$ & Banyak & 1 \\
\hline$<=75 \%$ & Sedang & 0.75 \\
\hline$<=50 \%$ & Sedikit & 0.5 \\
\hline$<=25 \%$ & Kurang & 0 \\
\hline
\end{tabular}

Tabel 4.6 Tabel Pembobotan Kriteria

\begin{tabular}{|l|r|r|r|r|r|}
\hline \multirow{2}{*}{ Alternatif } & \multicolumn{7}{|c|}{ Kriteria } \\
\cline { 2 - 7 } & C1 & C2 & C3 & C4 & \multicolumn{1}{l|}{ C5 } \\
\hline A1 & 0.5 & 0.5 & 0.75 & 1 & 0.5 \\
\hline A2 & 0.75 & 0.75 & 0.75 & 1 & 1 \\
\hline A3 & 0.5 & 0.5 & 0.75 & 1 & 0.5 \\
\hline A4 & 0.75 & 0.75 & 0.75 & 1 & 0.5 \\
\hline A5 & 0.5 & 0.75 & 0.75 & 0.75 & 0.5 \\
\hline
\end{tabular}


Tabel 4.7 Pembobotan

\begin{tabular}{|l|l|r|}
\hline Kriteria & Keterangan & Bobot \\
\hline C1 & Akreditas & 0.3 \\
\hline C2 & Fasilitas & 0.3 \\
\hline C3 & Biaya & 0.2 \\
\hline C4 & Lokasi & 0.1 \\
\hline C5 & Dosen & 0.1 \\
\hline \multicolumn{2}{|c|}{ Total } & 1 \\
\hline
\end{tabular}

Matriks

$\mathrm{X}=\left|\begin{array}{rrrrr}0.5 & 0.5 & 0.75 & 1 & 0.5 \\ 0.75 & 0.75 & 0.75 & 1 & 1 \\ 0.5 & 0.5 & 0.75 & 1 & 0.5 \\ 0.75 & 0.75 & 0.75 & 1 & 0.5 \\ 0.5 & 0.75 & 0.75 & 0.75 & 0.5\end{array}\right|$

Perhitungan Normalisasi

Dari contoh kasus ini yang akan menjadi kriteria cost adalah Kriteria Biaya. Sedangkan Kriteria Akreditas, Fasilitas, Lokasi dan Dosen menjadi kriteria Benefit. Untuk normalisasi nilai, jika factor kriteria cost digunakan rumusan

$\operatorname{Rij}=(\min \{x i j\} / x i j)$

Maka nilai-nilai normalisasi cost menjadi:

$\mathrm{R} 13=\min \{0.75 ; 0.75 ; 0.75 ; 0.75 ; 0.75\} / 0.75=,0.75 / 0.75=1$

$\mathrm{R} 23=\min \{0.75 ; 0.75 ; 0.75 ; 0.75 ; 0.75\} / 0.75=,0.75 / 0.75=1$

$\mathrm{R} 33=\min \{0.75 ; 0.75 ; 0.75 ; 0.75 ; 0.75\} / 0.75=,0.75 / 0.75=1$

$\mathrm{R} 43=\min \{0.75 ; 0.75 ; 0.75 ; 0.75 ; 0.75\} / 0.75=,0.75 / 0.75=1$

$\mathrm{R} 53=\min \{0.75 ; 0.75 ; 0.75 ; 0.75 ; 0.75\} / 0.75=,0.75 / 0.75=1$

Untuk normalisasi nilai, jika faktor kriteria benefit digunakan rumusan

$\mathrm{Rij}=(\mathrm{xij} / \max \{\mathrm{xij}\})$

Maka nilai - nilai normalisasi benefit menjadi:

$\mathrm{R} 11=0.5 / \max \{0.75 ; 0.75 ; 0.75 ; 0.75 ; 0.75\} / 0.75,)=0.5 / 0.75=0.67$

$\mathrm{R} 21=0.75 / \max \{0.75 ; 0.75 ; 0.75 ; 0.75 ; 0.75\} / 0.75,)=0.75 / 0.75=1$

$\mathrm{R} 31=0.5 / \max \{0.75 ; 0.75 ; 0.75 ; 0.75 ; 0.75\} / 0.75,)=0.5 / 0.75=0.67$

$\mathrm{R} 41=0.75 / \max \{0.75 ; 0.75 ; 0.75 ; 0.75 ; 0.75\} / 0.75,)=0.75 / 0.75=1$

$\mathrm{R} 51=0.5 / \max \{0.75 ; 0.75 ; 0.75 ; 0.75 ; 0.75\} / 0.75,)=0.5 / 0.75=0.67$

$\mathrm{R} 12=0.5 / \max \{0.75 ; 0.75 ; 0.75 ; 0.75 ; 0.75\} / 0.75,)=0.5 / 0.75=0.67$

$\mathrm{R} 22=0.75 / \max \{0.75 ; 0.75 ; 0.75 ; 0.75 ; 0.75\} / 0.75,)=0.75 / 0.75=1$

$\mathrm{R} 32=0.5 / \max \{0.75 ; 0.75 ; 0.75 ; 0.75 ; 0.75\} / 0.75,)=0.5 / 0.75=0.67$

$\mathrm{R} 42=0.75 / \max \{0.75 ; 0.75 ; 0.75 ; 0.75 ; 0.75\} / 0.75,)=0.75 / 0.75=1$

$\mathrm{R} 52=0.5 / \max \{0.75 ; 0.75 ; 0.75 ; 0.75 ; 0.75\} / 0.75,)=0.5 / 0.75=0.67$ 


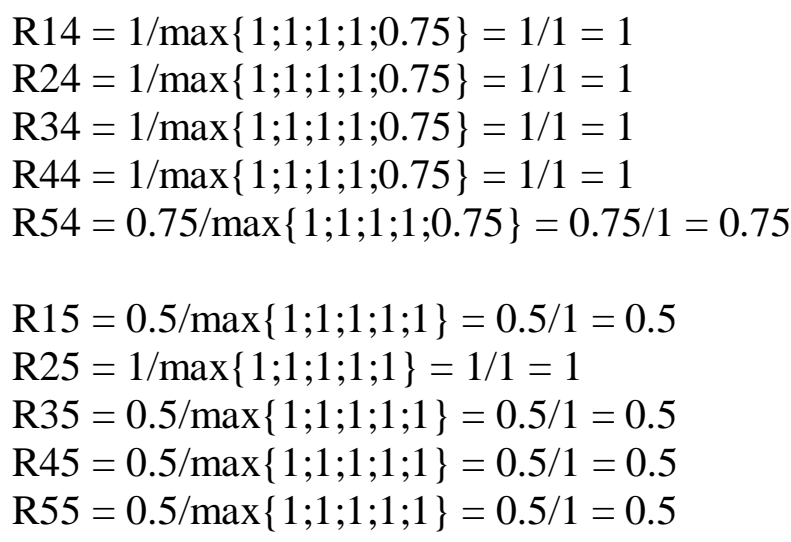

Hasil Normalisasi

$\mathrm{R}=\left|\begin{array}{rrrrr}0.67 & 0.67 & 1 & 1 & 0.5 \\ 1 & 1 & 1 & 1 & 1 \\ 0.67 & 0.67 & 1 & 1 & 0.5 \\ 1 & 1 & 1 & 1 & 0.5 \\ 0.67 & 1 & 1 & 0.75 & 0.5\end{array}\right|$

Perangkingan

$V i=\sum_{j=1}^{n} w_{j} \cdot r_{i j}$

$\mathrm{V} 1=(0.3 * 0.67)+(0.3 * 0.67)+(0.2 * 1)+(0.1 * 1)+(0.1 * 0.5)=0.75$

$\mathrm{V} 2=(0.3 * 1)+(0.3 * 1)+(0.2 * 1)+(0.1 * 1)+(0.1 * 1)=1$

$\mathrm{V} 3=(0.3 * 0.67)+(0.3 * 0.67)+(0.2 * 1)+(0.1 * 1)+(0.1 * 0.5)=0.75$

$\mathrm{V} 4=(0.3 * 1)+(0.3 * 0.67)+(0.2 * 1)+(0.1 * 1)+(0.1 * 0.5)=0.95$

$\mathrm{V} 5=(0.3 * 0.67)+(0.3 * 1)+(0.2 * 1)+(0.1 * 0.75)+(0.1 * 0.5)=0.825$

Dari hasil perangkinan Vi didapatkan nilai yang tertinggi yaitu V2, maka V2 yang akan dipilih sebagai Perguruan Tinggi terbaik sesuai dengan kriteria. Berikut merupakan tabel hasil perangkingan dari sampel Perguruan Tinggi yang digunakan.

Tabel 4.8 Penentuan Rangking

\begin{tabular}{|c|c|c|c|c|}
\hline No & Nama Perguruan Tinggi & Nilai & Persentase & Rangking \\
\hline 1 & Perguruan Tinggi B (A2) & 1 & $100 \%$ & 1 \\
\hline 2 & Perguruan Tinggi D (A4) & 0,95 & $95 \%$ & 2 \\
\hline 3 & Perguruan Tinggi E (A5) & 0,825 & $83 \%$ & 3 \\
\hline 4 & Perguruan Tinggi A (A1) & 0,75 & $75 \%$ & 4 \\
\hline 5 & Perguruan Tinggi C (A3) & 0,75 & $75 \%$ & 4 \\
\hline
\end{tabular}




\section{Kesimpulan}

Dari penelitian yang dilakukan dapat disimpulkan bahwa

1. Berdasarkan hasil penelitian dalam menerapkan Sistem Pendukung Keputusan menggunakan metode SAW ini dapat membantu pengguna dalam menentukan pemilihan Perguruan Tinggi.

2. Hasil Sistem Pendukung Keputusan ini memberikan peringkat pertama dengan Nilai Preferensi (Vi) yang terbesar. Adapun pada penelitian ini nilai Preferensi (Vi) yang terbesar adalah V2, yakni Perguruan Tinggi B (A2).

3. Untuk mendapatkan hasil yang optimal, bisa menggunakan banyak sampel data Perguruan tinggi agar dapat mengetahui hasil perangkingan yang lebih akurat.

\section{DAFTAR PUSTAKA}

[1] Djmain, Yusni. 2015. Sistem Pendukung Keputusan Penerimaan Pegawai Baru PT. PLN (PERSERO) Kantor Pusat Dengan Menggunakan Metode Simple Additive Weighting (SAW). Jurnal Teknik Informatika,Vol. 8 No. 1 April 2015.

[2] Eniyati, Sri. 2011. Perancangan Sistem Pendukung Keputusan untuk Penerimaan Beasiswa dengan Metode SAW (Simple Additive Weighting). Jurnal Teknologi Informasi DINAMIK Volume 16, No.2, Juli 2011 : 171-176. ISSN : 0854-9525

[3] Indrawaty, Youlia, dkk. 2011. Implementasi Simple Additive Weighting Pada Sistem Pengambilan Keputusan Sertifikasi Guru . Jurnal Informatika, Vol. 2, No.2. MeiAgustus 2011. Itenas library.

[4] Riandari, Fristy. 2017. Sistem Pendukung Keputusan Menggunakan Metode TOPSIS Dalam Memilih Kepala Departemen Pada Kantor Balai Wilayah Sungai Sumatera II Medan. Journal Of Informatic Pelita Nusantara, Volume 2, No. 1 Oktober 2017. EISSN 2541-3724

[5] Zulita, Leni Natalia. 2013. Sistem Pendukung Keputusan Menggunakan Metode SAW Untuk Penilaian Dosen Berprestasi (Studi Kasus Di Universitas Dehasen Bengkulu). Jurnal Media Infoatama, Vol. 9, No. 2, September 2013

[6] http://www.dikti.org/kpptjp/BAB_3.htm 